\title{
Working conditions as a socio-economic significant category
}

\author{
E. V. Alekina ${ }^{1, *}$, O. S. Popkova ${ }^{2}$, G. N. Yagovkin ${ }^{1}$, and B.K. Shapkenov ${ }^{3}$ \\ ${ }^{1}$ Samara State Technical University, Samara, Russia \\ ${ }^{2}$ Kazan State Power Engineering University, Kazan, Russia \\ ${ }^{3}$ S. Toraighyrov Pavlodar State University, Pavlodar, Kazakhstan
}

\begin{abstract}
The paper identifies the main components of the socio-economic category "working conditions", including all socio-economic and organizational-technical factors influencing the person's preparation for active participation in work activities without accidents and other incidents, which is an objective necessity in modern society.
\end{abstract}

\section{Introduction}

One of the main activities of the state is its policy aimed at social development, i.e., increase social benefits for the population. It is closely linked with economic policy and depends heavily on it. The latter is a system of structural investment and other measures aimed at ensuring a decent level, quality of life, and ensuring the safety of activities.

Improving working conditions provides the strategic objective of a labor economy and contributes to its sustainable development. In this regard, it is necessary to determine what methodologically represents the essence of the category "Working conditions" both for natural science research and for choosing the right direction when practicing enterprise problems related to this field. To understand the essence of the content of this category, one should rely on the analysis of the objective laws and processes occurring by it $[1,2]$. The socioeconomic nature of the category of "working conditions" is organically derived from the social nature of labor and is ultimately determined by the level of development of the productive forces and the dominant production relations in society.

This methodological position is essential when considering and determining the basic principles and directions for ensuring favorable working conditions [3]. The improvement of working conditions in modern society is an objective necessity and is organically linked with the solution of the problem of the complete satisfaction of the material and cultural needs of man, the transformation of labor into the first vital need. This is primarily the social nature and focus of improving working conditions in enterprises. The socio-economic working conditions include all factors that influence the preparation of a person to participate in labor activity actively, and on the restoration of the labor force expanded during the whole labor activity. They can be combined into two basic principles [4].
Socio-economic:

1) regulatory and legislative regulation of socioeconomic and industrial working conditions (working hours and work and rest schedules, sanitary norms and requirements, a system for monitoring compliance with applicable laws, norms, and rules in the field of occupational safety and health);

2) social and psychological factors characterizing the attitude of the employee to the organization and working conditions, the psychological climate in the production teams, the effectiveness of the benefits and compensation for work that are inevitably associated with adverse effects.

Organizational and technical:

1) means of labor (industrial buildings and facilities, sanitary appliances, technological equipment, tools, appliances, including tools that provide technical safety of labor);

2) the objects of labor and the product of labor (raw materials, materials, workpieces, semi-finished products, finished products);

3) technological processes (physical, mechanical, chemical and biological effects on the processed objects of labor, methods of their transportation and storage, etc.);

4) the organizational forms of production, labor and management (the level of specialization of production; its scale and mass; the shift operation of the enterprise; discontinuity and continuity of production; forms of division and cooperation of labor; techniques and methods; applicable modes of work and rest during the work shift, week, year; organization of service of the workplace; structure of the enterprise and its divisions; the ratio of functional and linear production management, etc.).

The socio-economic working conditions include all factors that influence the preparation of a person to participate in labor activity actively, and on the restoration of the labor force expanded during the whole labor activity.

\footnotetext{
* Corresponding author: Alekina-samgtu@mail.ru
} 
In the more developed recommendations, which are currently relevant [5], the concept of "working conditions" was summarized as follows:

"Working conditions" is a complex objective social phenomenon that is formed in the process of labor under the influence of interrelated factors of a socio-economic, technical, organizational and natural nature and affects the health, efficiency of a person, his attitude to work and the degree of satisfaction with it, on efficiency labor and other economic results of production, on the standard of living and the all-round development of "man as the main productive force of society".

Socio-economic analysis of the concept of "working conditions" leads to the conclusion that for a rational solution of issues of their full improvement it is essential not only to objectively assess the impact of all components: the elements of working conditions on a person - his performance, health, mood, well-being, etc., but also to establish the causes, factors affecting their formation [6-8].

\section{Method}

Based on this methodological position, two groups of factors are singled out, which act as the reasons for the formation and change of working conditions.

The first group includes social and economic factors, i.e., such, the action of which determines the nature of working conditions and is due to the dominant production relations in society. This group includes: regulatory and legislative state regulation of socioeconomic and industrial working conditions (working hours and work and rest schedules, sanitary standards and requirements, system of state and public control over compliance with applicable laws, norms, requirements and rules in the field of conditions labor, etc.); sociopsychological factors characterizing the attitude of workers to work and to the conditions in which it takes place, the psychological climate in production teams, the effectiveness of benefits and compensation for work that are inevitably associated with the adverse effects of working conditions on workers.

This group of factors includes the social impact on workers (motivation) in order to create healthy and safe working conditions at various levels of organization production levels.

The second group includes technical and organizational factors that have a direct impact on the formation of tangible elements of working conditions at workplaces, sites, workshops, and the enterprise as a whole. The effect of these factors reflects the scientific and technological progress in all its diversity of influence on technology, technology, and organizational forms of production and labor.

When considering the elements that make up the working conditions, it is necessary to proceed primarily from the principle of the unity of the human body and its environment. It can be balanced, and then the working conditions are qualitatively evaluated as favorable, or unbalanced due to the negative influence of any elements. Working conditions in this sense are assessed as unfavorable.

Favorable should be considered working conditions, when the quantitative and qualitative combination of their constituent elements has an impact on a person, contributing to the spiritual and physical development of the personality, the formation of creative attitude to work among employees, and a feeling of satisfaction with them. The adverse conditions include the working conditions, when their impact can cause a person to experience profound fatigue, which, accumulating, can lead to a painful condition or cause a professional pathology; Due to the adverse effect of working conditions, workers may form a negative opinion about work (unattractive, unpopular, low prestigious, etc.) $[9,10]$.

Our country is guided by a social development policy aimed at creating favorable working conditions for workers both in society as a whole and for each person. With the increase in the energy supply of production, especially at hazardous production facilities, the role of working conditions for ensuring the health and safety of workers increases. The problem is deepened by the increase in labor losses and the cost of labor and material resources in a market economy. In developed countries, successful business and socio-economic development of the state are possible only with a low level of injury and occupational morbidity.

Receipt by workers of insignificant compensation for work in harmful and dangerous working conditions misleads them, and from employers creates the illusion of caring for an employee. Some are not able to critically evaluate the future or current state of their health, while others show indifference to the health of their employees. Such mutual indifference does not induce the employees of the enterprise to take appropriate measures to ensure healthy working conditions, and employers - to eliminate harmful factors or change production technology. Currently, about $40 \%$ of workers receive compensation for unsatisfactory working conditions [11]. Given these circumstances, the problem of preserving the health of workers becomes a political one, since its solution requires an integrated approach.

\section{Results}

The economic importance of working conditions is determined by the effectiveness of measures to improve working conditions and increase occupational safety and is an economic expression of the social significance of working conditions. The economic importance of working conditions is determined by the results of changes in social indicators, which are determined by the following economic factors [12].

1. Increasing labor productivity, and, consequently, economic results of the enterprise's activities by creating comfortable working conditions, for example, by ensuring optimal parameters of the microclimate, lighting, and light environment, taking into account psychophysical and ergonomic features of labor, forming 
optimal work and rest schedules, therapeutic and preventive measures.

2. They have increased working time by reducing absenteeism due to injuries and illnesses. Attention should be paid to the fact that working conditions have a significant impact not only on occupational morbidity but also on the occurrence and duration of common diseases.

3. Cost savings on guarantees and compensation for work in adverse working conditions. Such guarantees and compensations, such as shorter working hours and additional leave, are associated with significant labor losses and are accompanied by payments of large sums of money for virtually unworked time. Such types of guarantees and compensations, such as an increase in tariff rates, preferential pensions, therapeutic and preventive nutrition, and free delivery of milk, also require large amounts of money. Creating conditions that comply with acceptable regulatory requirements allows for the partial or full reduction of these costs.

4. Decreased efficiency due to staff turnover in working conditions. Hard work, unfavorable sanitary and hygienic working conditions, the monotony of work, etc. are essential reasons for the dismissal of workers on their own. Labor turnover causes significant economic damage to the enterprise since It requires the cost of funds for the process of dismissal-recruitment, the process of training and internship of the newly enrolled. At the same time, before acquiring the necessary experience and skills, the productivity of work that has been resumed at work is small.

The social significance of working conditions also contributes to the growth of the efficiency of social production through their continuous improvement and improvement, the improvement of occupational safety, and the reduction of occupational injuries and morbidity.

It has been established that the improvement of working conditions leads to an increase in labor productivity and vice versa. For example, labor productivity in some types of work can be reduced by up to $50 \%$ when operating in conditions of high temperatures $(+30)$, production noise can reduce labor productivity from 5 to $20 \%$, and good lighting increases labor productivity by $10-15 \%$. Increases productivity and compliance with the requirements of technical aesthetics. In general, a set of measures to improve working conditions can lead to an increase in labor productivity by up to $30 \%$ [13-15].

\section{Discussion}

In this regard, the social significance of working conditions is manifested, first of all, in the influence on the change of the following three leading indicators characterizing the level of development of social production.

Labor productivity growth as a result of an increase in the fund of working time due to:

- Reduction of interstate downtime by preventing premature fatigue, as well as reducing the number or eliminating microtraumas caused by unfavorable working conditions. Preventing premature fatigue by rationalizing working conditions, introducing optimal work and rest schedules, and other activities at food enterprises help to increase the efficient use of working time. The same result gives the elimination of microtraumas, as each of them is accompanied by a loss of up to two hours of working time;

- reduction of whole-day loss of working time as a result of the reduction or elimination of temporary disability due to industrial injuries, occupational and general morbidity.

Reduction of labor resources and increase of professional activity of workers due to:

-improve the health of workers and increase their average life expectancy by improving working conditions, which is also accompanied by an increase in the work experience of workers with their high labor activity;

- professional development due to the growth of skills due to the increase in production experience;

-The ability to use residual labor activity, extensive practical experience, and professional knowledge of oldage pensioners and people with disabilities in work available to them and ensuring appropriate working conditions for their physical abilities.

3. The increase in the total national product by improving the above indicators and their constituent components [8]. Indicators of social effect also include:

- reduction of moral costs associated with the improvement of occupational safety;

-increase free time;

- maintaining a good mood;

-an increase in labor resources by reducing the number of days of illness, etc.

The social effect is not always possible to determine in monetary terms, but its significance is high.

The effectiveness of all activities in the field of ensuring favorable working conditions and the implementation for this purpose of scientific, technical and economic resources that modern society allocates mostly depends on the organizational forms in which this activity is carried out and the introduction of methods of managing working conditions.

In modern society, objective prerequisites are being created for purposeful use of the achievements of scientific and technological progress in the interests of the workers, the whole society for solving such tasks as enhancing the creative nature of labor, eliminating significant differences between mental and physical labor, creating favorable working conditions in every workplace. Meet modern scientific requirements, etc.

Successful realization of objective prerequisites for achieving this goal largely depends on the coherence of the mechanism of influence of the control system on all those factors that predetermine the formation of working conditions, their change, and development by objective and dynamic processes occurring in the social production of developed socialism. In connection with this, the management of working conditions is an organic link in the global system of production management and labor, which is its subsystem. This reflects the objective and natural unity of the goal of 
managing production, social labor, and its conditions, which are inherent in modern social relations, developing in the direction of the transformation of labor into the first vital human need.

\section{References}

[1] B.G. Zbyshko, Features of social and labor relations in the field of labor protection Labor Protection and Economics 4(29), 4-8 (2017)

[2] E.V. Alekina, D.A. Melnikova, G.N. Yagovkin, The theoretical basis for the formation of an integrated production safety management system: Monograph Samara: Samar. Go Tech. University Press 281 (2018)

[3] V.G. Makushin, Improving working conditions in enterprises: (Socio-economic problems): Economics 216 (1981)

[4] V.A. Spivak, Personnel Management Eksmo 121-124 (2010)

[5] $\mathrm{R}$ 2.2.2006-05 Occupational health. Guidance on the hygienic assessment of factors of the working environment and the labor process. Criteria and classification of working conditions.

[6] A.M. Elin, 2018 Transformation of social and labor relations: legal organizational and scientificmethodological principles and procedures of labor protection. Monograph M. De'Libri 534

[7] N.K. Kulbovskaya, Economics of labor protection Monograph - M .: Economy 247 (2011)

[8] G.E. Slezinger, Labor in a market economy INFRA-M (1996)

[9] Economic aspects of the working environment. Translation from English under the general ed. Prof., Dr. of Sc. EV Petrosyants. - M.: Scientific Center of social and industrial problems of labor protection 107 (1999)

[10] J. Sumelahti, L. Bjurström, E. Cooney, What is the price of absenteeism? In: Economic Aspects of the Production Environment: Translated from English. Under total ed. Prof. Dr. of Sc. EV Petrosyants 33-43 (1999)

[11] M. Hurmalainen, V. Husberg, The economic approach to monitoring the state of labor protection. Labor Protection Congress. Moscow 21 (2000)

[12] A.I. Amosha, Economic justification of labor protection measures Naukova Dumka 202 (1979)

[13] M. Bem, E. Veltri, E. Kleinsorge, Cost of safety Professional safety 22-29 (2004)

[14] V.S. Serdyuk, E.V. Bakiko, Economic damage from unfavorable working conditions VostokService 2 50-58 (2010)

[15] S.N. Yashin, Using the system of cost indicators in the economics of occupational safety Safety and labor protection 116 (2008) 